\title{
OS PARADIGMAS DA ESTRUTURA CURRICULAR DAS PRIMEIRAS FACULDADES DE DIREITO NO BRASIL
}

\section{CURRICULAR STRUCTURE PARADIGMS OF THE FIRST COURSES OF LAW IN BRAZIL}

\section{Carlos Renan Moreira Bretas* Maria Alice Nunes Costa ${ }^{\star \star}$}

\begin{abstract}
Resumo: Este artigo analisa o surgimento das primeiras faculdades de Direito no Brasil, em 1827, em Olinda e São Paulo. Os novos cursos pouco significaram em termos de produção científica na primeira metade do século XIX, sendo observado, apenas na segunda metade daquele século, um aumento de sua expressividade acadêmica, sobretudo em Pernambuco, com a transferência da faculdade de Olinda para Recife, em 1854. Influenciadas por paradigmas liberais, o objetivo das faculdades era formar um corpo qualificado para atender aos interesses administrativos do Estado que se desenvolvia após a Independência. Se por um lado, em Recife, havia a preponderância de pressupostos influenciados pelo evolucionismo, cientificismo e culturalismo - sobretudo em razão de Tobias Barreto - por outro lado, em São Paulo, preponderava o pragmatismo e o ensino do Direito Civil, atendendo às necessidades das elites oligárquicas no que diz respeito a direitos contratuais e de propriedade. Ainda na segunda metade do século XIX, algumas reformas foram implementadas nos currículos acadêmicos. Nesse período, ainda, a Igreja perdeu influência na educação e no Estado e passou a não mais ter o poder de intervir no ensino, tornando-se esse "livre".
\end{abstract}

Palavras-chave: Faculdade de Direito. Currículo Educacional de Direito. Século XIX. Brasil.

Abstract: This article analyzes the first Brazilian Law schools emergence in 1827 in the cities of Olinda and São Paulo. In the first half of the nineteenth century, the new courses were not significant in terms of scientific production. But in the second half of that century, there were an increase in the academic expressiveness of the faculties, especially observed in Pernambuco, when the course was transferred from Olinda to Recife in 1854. Influenced by liberal paradigms, the objective of the colleges was to form a qualified body to attend to the administrative State's interests. If on the one hand, in Recife, it has a preponderance of presuppositions influenced by the evolutionism, scientism and culturalism, mainly due to Tobias Barreto; on the other

* Doutorando e Mestre em Ciências Jurídicas e Sociais pelo Programa de Pós-Graduação em Sociologia e Direito da Universidade Federal Fluminense (PPGSD/UFF). Bacharel em Direito pela Universidade Federal do Estado do Rio de Janeiro (UNIRIO). Advogado. E-mail: carlos.renan28@hotmail.com.

"Pós-Doutorada em Sociologia pelo Centro de Estudos Sociais da Universidade de Coimbra (CES/UC). Doutora em Planejamento Urbano e Regional pela Universidade Federal do Rio de Janeiro (UFRJ/IPPUR). Mestre em Ciência Política pela Universidade Federal Fluminense (UFF). Professora associada da Universidade Federal Fluminense no Instituto de Arte e Comunicação Social e do Programa de Pós-Graduação em Sociologia e Direito da Universidade Federal Fluminense (PPGSD/UFF). E-mail: alicecosta.rj@uol.com.br. 
hand, in São Paulo, pragmatism and teaching of Civil Law prevailed, meeting the oligarchic elites needs, with regard to contractual and property rights. Even in the second half of the nineteenth century, some reforms were implemented in the curriculum. The Catholic Church has lost influence in education and the government has not been able to intervene in teaching, becoming this "free".

Keywords: Law Courses. Law Teaching. 19th Century. Brazil. 


\section{INTRODUÇÃO}

A passagem do Brasil, de Colônia Portuguesa a Império, em 1822, abriu um capítulo da História marcado por diversas mudanças sociopolíticas, econômicas, institucionais e jurídicas. Revoltas como a Revolução Pernambucana, em 1817, a Confederação do Equador, em Pernambuco, em 1824, a Guerra dos Farrapos, na Província de São Pedro do Rio Grande do Sul, entre 1835 e 1845, a Revolta Liberal, em São Paulo, em 1842, a Sabinada, na Bahia, em 1837; transformações jurídicas ocorridas através da Constituição outorgada em 1824 e de leis "abolicionistas", como a Lei Eusébio de Queiroz, em 1850, a Lei do Ventre Livre, em 1871, a Lei do Sexagenário em 1885 e a Lei Áurea, em 1888; e finalmente a proclamação da República, em 1889, são exemplos de acontecimentos que efervesceram o século XIX no Brasil. E nesse contexto de transformações políticas, surgem as primeiras Faculdades de Direito no Brasil, em 1827, nas cidades de Olinda e de São Paulo.

O objetivo que existia no momento da criação das novas faculdades de Direito não era a formação de advogados para defenderem os direitos da sociedade e dos habitantes do país. A principal preocupação era a formação de uma elite que pudesse dar conta dos problemas administrativos do Estado, haja vista que o processo de independência demandava a consolidação de um quadro de profissionais que pudessem lidar com a burocracia do aparelho estatal.

Na primeira metade do século XIX, os novos cursos pouco significaram em termos de relevância de produção acadêmica. Com más instalações e faltas de professores e alunos em Olinda, observava-se um marasmo típico do período colonial. Em São Paulo, as faculdades de Direito também pouco importaram em termos científicos, na primeira metade do século XIX.

Somente na segunda metade daquele século, a partir de diversas reformas nos cursos de Direito, as faculdades passaram a deter uma relevância intelectual maior. Em Pernambuco, no ano de 1854, a faculdade de Direito transfere-se de Olinda para Recife. Trata-se de uma mudança não só geográfica, mas também simbólica, que implicou um maior destaque científico do curso de Direito de Recife.

É ainda nesse período que se sucederam algumas reformas no currículo das faculdades. Em 1854, houve uma reforma no sentido de dar mais rigor disciplinar aos cursos, sobretudo em razão da generalizada desobediência que existia quando a faculdade estava instalada em Olinda. Em 1879, com a "Reforma do Ensino Livre", o 
Estado perdeu o seu poder de intervenção no ensino, e o curso de Direito foi desmembrado em duas seções: Ciências Jurídicas e Sociais, sendo esta última mais voltada para a formação de profissionais aptos a lidar com as questões administrativas do Estado. Ainda na segunda metade do século XIX, a influência da Igreja no ensino jurídico se enfraqueceu ${ }^{1}$, fato que é um reflexo da própria fragilização da relação Estado-Igreja.

\section{CRIAÇÃO DAS FACULDADES DE DIREITO DE OLINDA E SÃO PAULO}

No Brasil, até a criação dos primeiros cursos de Direito em Olinda e São Paulo, em 1827, os cargos correspondentes à função jurisdicional no país eram ocupados, exclusivamente, por quem tivesse formação em Direito na Universidade de Coimbra, em Portugal, além de dois anos de experiência, que permitiam ao candidato ser selecionado na chamada "Leitura dos Bacharéis", pelo Desembargo do Paço em Lisboa. (SILVA, 2005, p. 169).

Sua carreira profissional iniciava-se como "Juiz de Fora"2, podendo subir ao cargo de ouvidor e, posteriormente, de corregedor. Após o cumprimento dessas etapas, finalmente era possível que o magistrado pudesse se tornar desembargador (WOLKMER, 2002, p. 65) ${ }^{3}$. Esses magistrados podiam atuar tanto em Portugal quanto no Brasil, ou em outras colônias portuguesas.

O acesso à magistratura era marcado por uma grande desigualdade. Os requisitos e procedimentos de seleção impunham o afastamento de grande parte da população ao acesso à magistratura. Como assinala Schwartz:

Nos séculos XVII e XVIII, Portugal tinha de 2 milhões a 3 milhões de habitantes. A grande maioria era constituída de camponeses ou formava o

\footnotetext{
1 Em razão disso, por exemplo, em 1879, a disciplina de Direito Eclesiástico passou a ter a sua frequência dada como opcional, Decreto oㅜ 7.247, de 19 de Abril de 1879, art. 23, § 6‥ (BRASIL,1879). 2 Segundo Medina, "o cargo de Juiz de Fora era o cargo inicial da carreira da magistratura. Nomeado pelo Rei, segundo o procedimento já referido, o Juiz de Fora era designado para servir em determinada comarca, pelo prazo de três anos. [...] O cargo de Juiz de Fora atendia a duplo objetivo da Coroa portuguesa: o de conferir maior autoridade às decisões, nas causas mais complexas, compensando a circunstância de a justiça ser exercida, em grande parte, por juízes leigos, àquela época, bem como o de proporcionar maior controle dos negócios locais, por parte do reino". (MEDINA, 1990, p. 213).

3 "Para ingressar na carreira, além da origem social, era condição indispensável ser graduado na Universidade de Coimbra, de preferência em Direito Civil ou Canônico, ter exercido a profissão por dois anos e ter sido selecionado através do exame de ingresso ao serviço público (a "leitura de bacharéis") pelo Desembargo do Paço em Lisboa. Sua atividade profissional começava como "juiz de fora", prosseguindo como ouvidor de comarca e corregedor. Somente após uma boa experiência na administração judiciária é que o magistrado era promovido a desembargador, podendo ser designado tanto para a Metrópole quanto para as colônias."
} 
proletariado rural. As diversas restrições ao ingresso no serviço real de homens com essas origens obviamente eliminavam uma grande camada da população. (SCHWARTZ, 2011, p. 234).

Portugal mantinha um exclusivismo no ensino do Direito. Ao atuarem na colônia, o objetivo principal dos agentes da Justiça era servir aos interesses da metrópole portuguesa, e não, obrigatoriamente fazer Justiça. A Justiça não estava relacionada aos anseios de uma sociedade, pois os magistrados que atuavam na colônia formavam uma elite distanciada da própria população. Nesse sentido, o período colonial no Brasil era caracterizado a partir do monopólio do ensino, oferecido pela Universidade de Coimbra, assim como por um corporativismo presente na carreira da magistratura. (WOLKMER, 2002, p. 91).

Esse quadro estimulou que as forças liberais provocassem um combate para a implementação de reformas institucionais, no que se refere ao sistema de Justiça no Brasil. Resultados dessa luta foram a promulgação da Constituição de 1824 e a criação das faculdades de Direito em Olinda e São Paulo, além do Código Penal de 1830 (WOLKMER, 2002, p. 91). Quando surgiram as primeiras faculdades de Direito, era muito presente o ideário liberal com o qual se lutava contra a dominação da metrópole. Contudo, o liberalismo adotado aqui contava com certas limitações, preservando alguns interesses das elites e mantendo a escravidão. (NEDER, 1998, p. $206)^{4}$.

O surgimento das faculdades de Olinda e São Paulo espelhava o anseio de uma elite pós-colonial que procurava consolidar a independência político-cultural e reestruturar o poder, ideologicamente, reforçando uma organização burocráticoadministrativa, que seria responsável por governar o país. Em razão disso, os novos cursos surgiram ao mesmo tempo em que ocorria o processo de independência e construção do Estado Nacional (ADORNO, 1988, p. 77) . $^{5}$ O objetivo que se pretendia com a fundação dos novos cursos de Direito não era formar prioritariamente

\footnotetext{
4 "Tanto em São Paulo, quando no Recife, os postulados liberais foram invocados na luta contra o monopólio metropolitano na qual engajara-se importantes segmentos ligados à grande propriedade agrária e escravista. O liberalismo foi adotado, no entanto, com limitações e resguardados os privilégios daqueles segmentos sociais e mantida a escravidão".

5 "A criação e fundação dos cursos jurídicos no Brasil, na primeira metade do século XIX, nutriu-se da mesma mentalidade que norteou a trajetória dos principais movimentos sociais que resultaram na autonomização política dessa sociedade: o individualismo político e o liberalismo econômico. A constituição do Estado nacional reclamou tanto a autonomização cultural quanto - e sobretudo - a burocratização do aparelho estatal."
} 
advogados para atender às necessidades da população, mas sim, atender tãosomente aos interesses do Estado. Com isso, segundo Wolkmer:

[...] as escolas de Direito foram destinadas a assumir duas funções específicas: primeiro, ser polo de sistematização e irradiação do liberalismo enquanto nova ideologia político-jurídica capaz de defender e integrar a sociedade; segundo, dar efetivação institucional ao liberalismo no contexto formador de um quadro administrativo-profissional. Contudo, essas funções distintas, mas interligadas, não deixam de revelar certa contradição, que, como demonstra Joaquim de A. Falcão, comprova-se na pretensão de serem, de um lado, defensoras dos princípios liberais, de outro, de fomentadoras da emergência de uma elite burocrática para o controle do poder. Ademais, fácil é perceber o paradoxo revelado quando "os ideais liberais, usados para a libertação da tutela colonial e emancipação nacional, pretendem legitimar e assegurar os privilégios herdados pela elite na sociedade estratificada, oriunda do período colonial". (WOLKMER, 2002, p. 80-81).

Os novos cursos jurídicos foram, portanto, criados para atender aos interesses do Estado em desenvolvimento e não para atender aos anseios da população (BASTOS, 1998, p. 14) ${ }^{6}$. A prioridade a qual se pretendia dar atenção relacionava-se a exigências institucionais; estas, basicamente, constituíam prioridades judiciais do Estado. (BASTOS, 1998, p. 15).

Além disso, a consolidação de uma elite conservadora, que se formava na Faculdade de Coimbra, Recife e São Paulo, em certa medida, colaborou para a construção de uma política que buscara construir um Império centralizado. (FAUSTO, 2015, p. 100).

Segundo Bastos, a distribuição das elites durante o Império se dava em três eixos de atuação, com objetivos muito parecidos, mas ainda assim, diferenciáveis, contando com limites institucionais bem evidentes. Havia a elite imperial, detentora do controle do Estado que acabara de se formar, mas que já se articulava com muita autonomia. Paralelamente, existia uma elite civil, dependente do Estado e que representava interesses rudimentares da sociedade civil. Essa elite não possuía seus próprios parâmetros políticos e, em razão disso, se articulava institucionalmente de acordo com os propósitos do Estado. Ao lado dessas duas elites, formou-se uma terceira, mais liberal e ao mesmo tempo resistente aos objetivos das outras duas elites. Essa nova elite civil, fracionada, engajou-se no processo de independência e

\footnotetext{
6 "Desta perspectiva, é bom que se ressalte: os cursos jurídicos não se organizaram para atender às expectativas judiciais da sociedade, mas sim aos interesses do Estado. Assim, devem-se ressaltar duas variantes importantes na criação dos cursos jurídicos no Brasil: seriam eles mais importantes que o ensino de grau inferior? Seria mais importante formar advogados para o trabalho judicial ou bacharéis que colaborassem na formação do Estado?"
} 
era composta por elites regionais. Em função disso, muitas vezes, seus interesses eram divergentes, e isso se refletia no debate acerca da criação dos novos cursos jurídicos no Brasil na primeira metade do século XIX. (BASTOS, 1998, p. 6).

No meio da disputa política entre as elites na discussão sobre as novas faculdades de Direito, restaram vitoriosas as frações das elites civis regionais, tanto conservadoras, quanto liberais. (BASTOS, 1998, p. 7) Com isso, a história da criação das primeiras faculdades de Direito no Brasil reflete, de forma evidente, a história das conciliações realizadas entre as elites da época, sobretudo entre frações da elite civil e elites imperiais (BASTOS, 1998, p. 7), que culminou na Lei de 11 de agosto de 1827 (BRASIL, 1827), que instituiu os novos cursos e suas cadeiras.

Segundo Gizlene Neder, no decorrer das longas discussões parlamentares antecessoras da implantação dos cursos de Direito em Recife e São Paulo, um dos debates diz respeito à localização das novas faculdades. Apesar do Rio de Janeiro ser a capital e estar vocacionada a sediar os novos cursos, restou vitoriosa a criação dos cursos no eixo Sul e Norte do país, nas cidades de São Paulo e Olinda, enquanto estratégia de articulação entre distintas regiões do país. Essa escolha tinha como consequência, também, a prevenção contra movimentos separatistas. Naquela época, já havia uma grande preocupação quanto à "importância de uma direção no processo de ideologização através da Educação, formulada em termos da formação de uma consciência nacional." (NEDER, 1998, p. 202-203) ${ }^{7}$.

A faculdade de Olinda, instalada em maio de 1828, no entanto, não conseguiu se desvencilhar das velhas ideologias portuguesas, tendo em vista que tudo que se formara nessa faculdade era oriundo de Portugal: os hábitos e, principalmente, grande parte do corpo discente e docente. Com isso, a faculdade se assemelhava justamente ao que se buscava eliminar referente à metrópole (SCHWARCZ, 2005, p. 144). Conforme assinala Gizlene Neder:

\footnotetext{
É certo que o ensino jurídico em Portugal influenciou sobremaneira a formação jurídica no Brasil desde a criação das Faculdades de Direito em Olinda (posteriormente transferida para Recife) e em São Paulo no ano de 1827. As referências a esta influência estão presentes em toda a literatura sobre o assunto. (NEDER, 1998, p. 195).
}

\footnotetext{
7 "Assim uma Faculdade, de Olinda (mais tarde o ensino foi transferido para Recife), serviria aos habitantes do Norte; a outra, em São Paulo, os do Sul. Mais ainda, apesar das enormes diferenças regionais, as Escolas de Direito estavam projetadas para promover a "unidade moral do organismo político brasileiro". Ou seja, no interior do processo de ideologização promovido a partir das Escolas de Direito, a prática ideológica (assim como também a prática política e a prática econômica) delas decorrentes, acabou por produzir efeitos que redundaram na construção do "nacional."
} 
Além disso, o período em que o curso ficou instalado em Olinda pouco representou historicamente. Foi uma escola inaugurada às pressas, que não contava com um corpo docente qualificado e, sobretudo, que estava fortemente influenciada pelos interesses da Igreja. Exemplo disso é o fato de a nova faculdade estar instalada no Mosteiro São Bento, espaço cedido pela própria Igreja, onde permaneceu o curso durante 22 anos. (SCHWARCZ, 2005, p. 144).

Esse período foi marcado também por grandes ausências de professores e alunos, sendo que, muitos professores, mal remunerados, alegavam morar em Recife, justificando a distância como o motivo para suas faltas. Diante disso, era de se esperar que 0 curso de Olinda fosse caracterizado pela baixa produção acadêmica e intelectual. A faculdade foi posteriormente instalada no Casarão do Hospício, ainda em Olinda, e finalmente transferida para Recife em 1854, devido a um grande incêndio. A transferência para Recife não representou apenas uma mudança geográfica, mas também implicou uma mudança intelectual (SCHWARCZ, 2005, p. 145-146), como veremos a seguir.

\section{IDEOLOGIAS E REFORMAS NAS FACULDADES DE DIREITO NO SÉCULO XIX}

A segunda metade do século XIX foi determinante para a transformação de certos paradigmas, no que tange ao ensino jurídico. Um efeito dessas mudanças foi o enfraquecimento da influência eclesiástica sobre o ensino do Direito, o que permitiu que certos professores lecionassem nas instituições, substituindo os antigos lentes imperiais ${ }^{8}$. (BASTOS, 1998, p. 56).

Isso permitiu que surgissem correntes de pensamento intelectuais revolucionárias, como a conhecida Escola de Recife, em que se destacavam, dentre seus integrantes, Tobias Barreto. A Escola de Recife, enquanto movimento, surge na década de 1860, e se estende até a década de 1920. (GOMES, 2015, p. 5).

Tobias Barreto foi o responsável pela introdução do culturalismo no Brasil, em oposição ao positivismo e o determinismo social de Augusto Comte, intelectual francês, bastante influente no país. Tobias Barreto não esperava que o positivismo

\footnotetext{
${ }^{8}$ Lentes era a designação dos responsáveis pela regência das cadeiras dos cursos de Olinda e São Paulo. Vide Lei de 11 de agosto de 1827, de cuja ementa se extrai: "Crêa dous Cursos de sciencias Juridicas e Sociaes, um na cidade de S. Paulo e outro na de Olinda".
} 
fosse responder às demandas da intelectualidade no país. Para Tobias Barreto, as pessoas eram resultado de um processo cultural e não um produto natural, conforme se defendia a partir de ideias positivistas. (GOMES, 2015, p. 5-6).

Enquanto Recife era marcado pelo "cientificismo, pelo germanismo e pelo evolucionismo"; em São Paulo, ao contrário, predominava o positivismo de Comte. Nesse sentido, "as concepções evolucionistas tiveram larga aceitação em Recife, sobretudo, após apropriação de ideias de Haeckel, Buckle, Spencer, Darwin, Littré, Le Play, Le Bon e Gobineau por Tobias Barreto." (PISCIOTTA, 2014, p. 5-6).

Segundo Gizlene Neder, enquanto a faculdade de Direito de Recife é marcada por uma temática pautada na Ilustração, São Paulo era caracterizada pelo pragmatismo, tipicamente característico do Pombalismo. O pensamento jurídico desenvolvido no curso de Recife, na visão da autora, permite o reconhecer como uma "Escola" de pensamento, composta por intelectuais de notável conhecimento. (NEDER, 1998, p. 205).

Paralelamente, a Academia de São Paulo constituiu-se como um polo de formação de pensadores "destinados à cooptação pela burocracia estatal, em razão de sua localização estratégica e, por estar no berço da oligarquia agrária paulista (WOLKMER, 2002, p. 83). A Academia paulista esteve vinculada a pressupostos liberais desde o momento da sua criação e, com o passar dos anos, estes pressupostos foram se adequando para atender aos anseios das oligarquias regionais. (NEDER, 1998, p. 205).

O ensino de Direito Natural era tema do primeiro ano dos novos cursos de Direito, assim como o era em Coimbra (PISCIOTTA, 2014, p. 6) ${ }^{9}$. Direito Natural, enquanto disciplina, esteve no currículo das faculdades de Direito durante todo o período Imperial, sendo apenas substituído com a proclamação da República, pela matéria de Filosofia do Direito. (PISCIOTTA, 2014, p. 8). Nesse sentido:

\footnotetext{
A tradição jusnaturalista entre nós pela figura singular de Tomás Antônio Gonzaga irá prosseguir, após a independência, com a criação por D. Pedro I das duas Faculdades de Direito - a de Olinda (depois Recife) e a de S. Paulo -, como resultado da produção científica e didática dos professores das primeiras cátedras de Direito Natural, que tiveram não só o empenho como o dever de redigir seus cursos em forma de livro-texto para o uso de seus alunos. Desse expediente resulta um considerável acervo de obras de Direito
}

\footnotetext{
9 "O primeiro momento da faculdade de Olinda/Recife tem como modelo o jusnaturalismo da Segunda Escolástica, fortalecido pela influência da Igreja na matéria. Os "Elementos de Direito Natural Privado" (1844), de Pedro Autran, representam o modelo da matéria no ensino pernambucano. Em São Paulo, o mesmo vale para o muito criticado "Princípios de Direito Natural", de Avelar Brotero".
} 
Natural produzidas por autores brasileiros em todo o correr do século XIX. (MACHADO NETO, 1969, p. 18).

Os cursos de Recife e São Paulo diferenciavam-se pela predominância curricular. Em São Paulo, o ensino de Direito Civil englobava o direito de propriedade e contratos (PISCIOTTA, 2014, p. 6). Enquanto em Recife, preponderava um ensino mais voltado à antropologia criminal. Recife tinha um ensino mais humanista, enquanto São Paulo voltava-se ao ensino que atendia aos interesses da política de sua elite regional. (SILVA, 2015, p. 4).

Em relação à estrutura curricular, é curioso notar a oferta da disciplina de Economia Política na Lei de 11 de agosto de 1827, que persistiu nas reformas curriculares subsequentes, em $1854^{10}, 1879^{11}$ e $1885^{12}$. Todos os projetos que foram apresentados nas discussões parlamentares continham essa disciplina, havendo poucas variações de um a outro. A Economia Política, enquanto disciplina, era o reflexo do objetivo dos novos cursos, na formação de uma elite pronta para lidar com os problemas do Estado, uma vez que ela "não se pretendia ensinar a advogar, mas a exercer determinadas funções no Estado" (BASTOS, 1998, p. 18). O mesmo se dava com outras matérias como "Estatística e Geografia Política, indicadas em outros projetos, [os quais] pretendiam transmitir regras e técnicas para o funcionamento do Estado e não métodos para a aplicação do Direito". (BASTOS, 1998, p. 18).

Em 1854, quando foi publicado o Decreto o 1.386 (BRASIL,1854), algumas mudanças curriculares foram implementadas. Estabeleceram-se o ensino de Direito Romano e Administrativo, assim como as disciplinas de Hermenêutica Jurídica, Processo Civil e Criminal, além da Prática Forense. (BASTOS, 1998, p. 54).

Essa reforma tinha por escopo garantir maior disciplina nos cursos de Direito, sobretudo em Recife, buscando combater a rotina de desobediência generalizada herdada de Olinda. As mudanças trazidas por essa reforma impuseram maior rigor nos exames de seleção, definiram um calendário regular de aulas, limitaram o número de reprovações e instituíram um severo sistema de castigos, incluindo até mesmo a "prisão correcional pelo diretor". (SCHWARCZ, 2005, p. 147).

Em 1879, é publicado o Decreto o 7.247 (BRASIL,1879), subscrito por Carlos Leôncio de Carvalho, que determinou a liberdade de ensino. A proposta do "Ensino 
Livre" era mudar o quadro até então presente no país, que consistia no monopólio do Estado sobre a educação (BASTOS, 1998, p. 80) ${ }^{13}$. O referido decreto não se restringiu apenas a "propostas moderadas de combinação entre a liberdade de ensino e a intervenção do Governo", mas determinou "como livre o ensino primário e secundário no município da Corte e o superior em todo o Império". Com isso, o Estado passou apenas a deter o direito de realizar inspeções para "garantir as condições de moralidade e higiene". (BASTOS, 1998, p. 81).

Com a reforma do "Ensino Livre", a partir do art. 23 do Decreto $n^{\circ} 7.247$ (BRASIL,1885) de 1879, as faculdades de Direito foram divididas em duas seções: a "das Sciencias Juridicas e a das Sociaes". O curso de Ciências Sociais consistia em uma tentativa de o Estado viabilizar sua Administração, ainda muito dependente de quadros eclesiásticos, mesmo na segunda metade do século XIX, e de pessoal não qualificado. Com isso, o curso de Ciências Sociais passou a concentrar disciplinas como Higiene Pública, Finanças e Contabilidade do Estado, Economia Política, Direito Administrativo (BASTOS, 1998, p. 87) ${ }^{14}$ e Direito das Gentes. Os principais debates da época concentravam-se nas questões primordiais do Estado da segunda metade do século XIX: "a separação do Estado-Igreja e a educação no Império, que também era uma questão do Estado, a liberdade de ensino". (BASTOS, 1998, p. 87).

Essa reforma estava inserida em um contexto muito mais amplo, relacionado a uma reviravolta no campo teórico, muito desejada por intelectuais que almejavam que o Direito se revestisse de um estatuto científico, distanciado de "influências religiosas e metafísicas então dominantes". (SCHWARCZ, 2005, p. 147).

É nessa reforma que a disciplina de Direito Eclesiástico deixa de ser obrigatória, conforme se extrai do art. $23, \S 6^{\circ}$ do referido decreto: "para a collação do gráo em qualquer das secções não se exigirá dos acatholicos o exame do direito ecclesiastico".

O objetivo essencial do Decreto $n^{0} 7.247$ de 1879 consistia na formação de pessoal qualificado para cuidar da Administração - através do curso de Ciências Sociais - e não apenas de magistrados e advogados, como no curso de Ciências

13 "O quarto tipo [de ensino superior], que simboliza o atraso, é o resto de um passado que se vai esboroando com a ação civilizadora do tempo; é o monopólio do Estado. É a este que ainda nos achamos filiados".

14 "Do ponto de vista curricular, o Decreto ํㅜ 7.247 de 1879 não apresentava grandes novidades, exceto, é claro, o deslocamento de algumas disciplinas do curso de Ciências Jurídicas para o Curso de Ciências Sociais, que ele criou". 
Jurídicas. Esta mudança, estabelecida com o surgimento da seção das Ciências Sociais, desafogou o curso de Ciências Jurídicas de um grande número de disciplinas. (BASTOS, 1998, p. 87).

Os debates que sucederam a Reforma do Ensino Livre de 1879 levaram a publicação do Decreto oำ 9.360, em 1885. Na realidade, os debates foram inseridos em um contexto extremamente tumultuado, poucos anos antes da proclamação da República. Este contexto evidencia a ausência de perspectivas bem delineadas naquele momento histórico, marcado pelo fim do Império e pela emergência de diversas questões, como a religiosa, a militar, a eleitoral e a da escravatura. Tais questões levaram à dissociação do Estado imperial, que não conseguiu atender aos interesses da Igreja - cada vez mais afastada dos assuntos administrativos - e desarticular os movimentos estudantis que se formaram e cresciam cada vez mais. Com isso, surge o Decreto no 9.360, em 1885, que trouxe algumas alterações legais, mas sem, no entanto, implementar um Plano Geral da Educação. (BASTOS, 1998, p. 108).

O referido decreto manteve certas alterações que já haviam sido implementadas na reforma do ensino livre em 1879. Mantiveram-se as duas seções das faculdades de Direito, em Ciências Jurídicas e Sociais, assim como se preservou a não obrigatoriedade de frequência na disciplina de Direito Eclesiástico, que já era opcional. O decreto também previu a possibilidade de abertura de cursos livres, que poderiam ser ofertados por bacharéis, doutores ou estrangeiros habilitados pelas faculdades do país. (BASTOS, 1998, p. 114-115).

\section{CONSIDERAÇÕES FINAIS}

Vimos que as faculdades de Direito surgem com forte influência do liberalismo. Contudo, o liberalismo aqui existente era marcado por diversas limitações, sempre preservando o interesse das elites e mantendo a escravidão. Com o passar do tempo, os pressupostos liberais presentes na Academia de São Paulo foram se moldando aos interesses das elites presentes naquela região, sobretudo agrárias.

Pudemos constatar diversas reformas realizadas ao longo da segunda metade do século XIX, que espelham ideologias e conflitos políticos que se desenvolveram na época. $O$ ensino passou a ser livre, e a Igreja gradativamente foi perdendo influência nas faculdades de Direito. 
São Paulo apresentava um ensino pragmático, com muita ênfase no Direito Civil, o qual se desdobra nos direitos de propriedade e dos contratos. A Academia de São Paulo consolidou-se como um centro de formação de intelectuais destinados à burocracia estatal, por estar localizada no seio da oligarquia rural paulista. Enquanto isso, Recife apresentava um ensino mais humanista, com forte influência do cientificismo e do evolucionismo, assim como do culturalismo, presente no pensamento de Tobias Barreto.

Nos anos compreendidos entre 1870 a 1930, São Paulo passou a concentrar um grande poder econômico e político, que se fortaleceu nas primeiras décadas do século $X X$, ao contrário dos 40 primeiros anos após a independência, em que a Academia de São Paulo se localizava em uma província que vivia "o mesmo marasmo dos tempos coloniais, segundo sugerem os historiadores que se ocuparam do estudo da formação dessa cidade" (ADORNO, 1988, p. 79-80). Paralelamente, Pernambuco passou a vivenciar uma decadência não só financeira, mas também política. (SCHWARCZ, 2005, p. 174).

\section{REFERÊNCIAS}

ADORNO, Sérgio. Os aprendizes do poder. Rio de Janeiro: Paz e Terra, 1988.

BASTOS, Aurélio Wander. O ensino jurídico no Brasil. Rio de Janeiro: Lumen Juris, 1998.

BRASIL. Decreto no 1.386, de 28 de abril de 1854. Dá novos Estatutos aos Cursos Juridicos. Rio de Janeiro: Império do Brasil, 1854.

BRASIL. Decreto no 7.247, de 19 de abril de 1879. Reforma o ensino primário e secundário no município da Côrte e o superior em todo o Império. Rio de Janeiro: Império do Brasil, 1879.

BRASIL. Decreto no 9.360, de 17 de janeiro de 1885. Dá novos Estatutos ás Faculdades de Direito. Rio de Janeiro: Império do Brasil, 1885.

BRASIL. Lei de 11 de agosto de 1827. Crêa dous Cursos de sciencias Juridicas e Sociaes, um na cidade de S. Paulo e outro na de Olinda. Rio de Janeiro: Império do Brasil, 1827.

FAUSTO, Boris. História concisa do Brasil. 3. ed. São Paulo: EdUSP, 2015.

GOMES, Adriana. A Escola de Recife e o culturalismo no pensamento jurídico brasileiro no oitocentos. In: SIMPÓSIO NACIONAL DE HISTÓRIA, 28., 2015, Florianópolis. Anais [...]. Florianópolis: ANPUH-SP, 2015. 
MACHADO NETO, Antônio Luiz. História das ideias jurídicas no Brasil. São Paulo: EdUSP, 1969.

MEDINA, Paulo Roberto de Gouvêa. A organização judiciária do Brasil-Colônia. Revista Brasileira de Direito Comparado, Rio de Janeiro, n. 40/41, p. 209-224, 1990.

NEDER, Gizlene. Coimbra e os juristas brasileiros. Revista Discursos Sediciosos: Crime, Direito e Sociedade, Rio de Janeiro, ano 3, n. 5-6, p. 195-214, 1998.

PISCIOTTA, Renato Matsui. Direito natural e juristas da Academia de Direito de São Paulo (1827-1850). In: ENCONTRO ESTADUAL DE HISTÓRIA DA ANPUH-SP, 22., 2014, Santos. Anais [...]. Santos: ANPUH-SP, 2014.

SCHWARCZ, Lilia Moritz. O espetáculo das raças: cientistas, instituições e questão racial no Brasil - 1870-1930. São Paulo: Companhia das Letras, 2005.

SCHWARTZ, Stuart B. Burocracia e sociedade no Brasil colonial: o Tribunal Superior da Bahia e seus desembargadores, 1609-1751. Tradução: Berilo Vargas. São Paulo: Companhia das Letras, 2011.

SILVA, Antônio Henrique Ferreira da. A faculdade de direito de Recife e a nova ordem social: o bacharelismo como fonte imaginária de poder. In: SIMPÓSIO NACIONAL DE HISTÓRIA, 28., 2015, Florianópolis. Anais [...]. Florianópolis: ANPUH-SP, 2015.

SILVA, Maria Beatriz Nizza da. Ser nobre na Colônia. São Paulo: UNESP, 2005.

WOLKMER, Antônio Carlos. História do direito no Brasil. Rio de Janeiro: Forense, 2002. 